\title{
THE $\boldsymbol{k}$-RAINBOW BONDAGE NUMBER OF A DIGRAPH
}

\author{
JAFAR AmJadi, NEgar MOHAmmadi \\ Seyed Mahmoud Sheikholeslami \\ Department of Mathematics \\ Azarbaijan Shahid Madani University \\ Tabriz, I.R. Iran
}

e-mail: \{j-amjadi;s.m.sheikholeslami\}@azaruniv.edu

AND

\author{
LUTZ VOLKMANN \\ Lehrstuhl II für Mathematik \\ RWTH Aachen University \\ 52056 Aachen, Germany
}

e-mail: volkm@math2.rwth-aachen.de

\begin{abstract}
Let $D=(V, A)$ be a finite and simple digraph. A $k$-rainbow dominating function $(k \mathrm{RDF})$ of a digraph $D$ is a function $f$ from the vertex set $V$ to the set of all subsets of the set $\{1,2, \ldots, k\}$ such that for any vertex $v \in V$ with $f(v)=\emptyset$ the condition $\bigcup_{u \in N^{-}(v)} f(u)=\{1,2, \ldots, k\}$ is fulfilled, where $N^{-}(v)$ is the set of in-neighbors of $v$. The weight of a $k \operatorname{RDF} f$ is the value $\omega(f)=\sum_{v \in V}|f(v)|$. The k-rainbow domination number of a digraph $D$, denoted by $\gamma_{r k}(D)$, is the minimum weight of a $k \mathrm{RDF}$ of $D$. The $k$-rainbow bondage number $b_{r k}(D)$ of a digraph $D$ with maximum in-degree at least two, is the minimum cardinality of all sets $A^{\prime} \subseteq A$ for which $\gamma_{r k}\left(D-A^{\prime}\right)>\gamma_{r k}(D)$. In this paper, we establish some bounds for the $k$-rainbow bondage number and determine the $k$-rainbow bondage number of several classes of digraphs.

Keywords: $k$-rainbow dominating function, $k$-rainbow domination number, $k$-rainbow bondage number, digraph.
\end{abstract}

2010 Mathematics Subject Classification: 05C69.

\section{REFERENCES}


[1] J. Amjadi, A. Bahremandpour, S.M. Sheikholeslami and L. Volkmann, The rainbow domination number of a digraph, Kragujevac J. Math. 37 (2013) 257-268.

[2] B. Brešar, M.A. Henning and D.F. Rall, Rainbow domination in graphs, Taiwanese J. Math. 12 (2008) 213-225.

[3] B. Brešar and T.K. Šumenjak, On the 2-rainbow domination in graphs, Discrete Appl. Math. 155 (2007) 2394-2400. doi:10.1016/j.dam.2007.07.018

[4] G.J. Chang, J. Wu and X. Zhu, Rainbow domination on trees, Discrete Appl. Math. 158 (2010) 8-12. doi:10.1016/j.dam.2009.08.010

[5] Ch. Tong, X. Lin, Y. Yang and M.Luo, 2-rainbow domination of generalized Petersen graphs $P(n, 2)$, Discrete Appl. Math. 157 (2009) 1932-1937. doi:10.1016/j.dam.2009.01.020

[6] N. Dehgardi, S.M. Sheikholeslami and L. Volkmann, The k-rainbow bondage number of a graph, Discrete Appl. Math. 174 (2014) 133-139. doi:10.1016/j.dam.2014.05.006

[7] J.F. Fink, M.S. Jacobson, L.F. Kinch and J. Roberts, The bondage number of a graph, Discrete Math. 86 (1990) 47-57. doi:10.1016/0012-365X(90)90348-L

[8] T.W. Haynes, S.T. Hedetniemi and P.J. Slater, Fundamentals of Domination in Graphs (Marcel Dekker, Inc. New York, 1998).

[9] D. Meierling, S.M. Sheikholeslami and L. Volkmann, Nordhaus-Gaddum bounds on the $k$-rainbow domatic number of a graph, Appl. Math. Lett. 24 (2011) 1758-1761. doi:10.1016/j.aml.2011.04.046

[10] S.M. Sheikholeslami and L. Volkmann, The k-rainbow domatic number of a graph, Discuss. Math. Graph Theory 32 (2012) 129-140. doi:10.7151/dmgt.1591

[11] D.B. West, Introduction to Graph Theory (Prentice-Hall, Inc., 2000).

[12] Y. Wu and N. Jafari Rad, Bounds on the 2-rainbow domination number of graphs, Graphs Combin. 29 (2013) 1125-1133. doi:10.1007/s00373-012-1158-y

[13] G. Xu, 2-rainbow domination in generalized Petersen graphs $P(n, 3)$, Discrete Appl. Math. 157 (2009) 2570-2573. doi:10.1016/j.dam.2009.03.016

Received 10 February 2014 Revised 12 June 2014 Accepted 12 June 2014 